\title{
PENGEMBANGAN KEMAMPUAN KOMUNIKASI KELUARGAUNTUK KADER JPPA KELURAHAN SADENG DALAM MEWUJUDKAN KOTA LAYAK ANAK
}

\author{
Naiza Rosalia $^{1 *}$, Mutia Rahmi Pratiwi ${ }^{1}$, Fibriyani Nuraliya ${ }^{1}$ \\ ${ }^{I}$ Ilmu Komunikasi, Fakultas Ilmu Komputer,Universitas Dian Nuswantoro, \\ Jl. Imam Bonjol No.205-207 Semarang \\ Email Penulisan Korespondensi: NaizaRosaliaahmad@gmail.com
}

\begin{abstract}
Abstrak
Tingginya angka kekerasan pada anak di kota Semarang yang mencapai 195 kasus di tahun 2018 perlu menjadi perhatian bagi pemerintah maupun masyarakat. Hal ini harus segera diatasi karena kota Semarang menargetkan menjadi Kota Layak Anak pada tahun 2020. Upaya telah dilakukan Pemkot Semarang namun belum berdampak signifikan pada penurunan angka kekerasan pada anak.Indikator Kota Layak Anak tidak hanya daritertanganinya anak korban kekerasan, namun juga bagaimana langkah preventif yang dilakukan. Komunikasi keluarga yang baik dapat menjadi benteng pertahanan awal pencegahan kekerasan pada anak.Hal ini menjadi dasar dilakukannyapengabdian masyarakat berupaworkshop mengenai pengembangan komunikasi keluarga untuk kader JPPA (Jaringan Perlindungan Perempuan dan Anak) Kelurahan Sadeng, Semarang.Peranan JPPA (Jaringan Perlindungan Perempuan dan Anak) Kelurahan Sadeng sudah menjadi embrio yang baik namun belum maksimal karena mereka hanya bertindak saat ada kasus namun tidak melaksanakan langkah preventif. Metode pelaksanaan dilakukan dengan pemberian materi dan pengukuran pemahaman peserta terkait komunikasi keluarga yang selama ini dipahami dan telah dilakukan.Hasil post test tertulis yang dilakukan menunjukan terjadi peningkatan kemampuan kamunikasi yang dimiliki oleh para peserta selaku Kader JPPA.
\end{abstract}

\section{Kata kunci:Komunikasi Interpersonal, Kota Layak Anak, Semarang}

\begin{abstract}
The high rate of violence against children in Semarang which reached 195 cases in 2018 needs to be a concern of all parties both government and society. This must be addressed immediately because the city of Semarang is targeting to became a city worthy of children by 2020. Semarang City Government has made various efforts but it has not yet had a significant impact on reducing the number of violence against children. The indicator of the City Worth Child is not only how children who are victims of violence can be handled properly, but also how to take action to prevent violence against children as a preventive act. Good communication in a family can certainly be a stronghold early in preventing violence against children. This became the basis of community service in the form of workshops related to the development of family communication for JPPA (Women's and Child Protection Network) Sadeng Village, Gunungpati District, Semarang. The role of JPPA in Sadeng Village has become a good embryo, but it is not optimal, because they only take action when their area cases but do not carry out preventive measures. The method of implementation was carried out by providing material and measuring the participant's understanding of family communication that had been understood and done. The result of the written post-test showed an increase in the communication skills possessed by the participants as JPPA Cadres.
\end{abstract}

\section{Keywords:Interpersonal Communication, City Worth Child, Semarang}




\section{PENDAHULUAN}

Menjaga lingkungan yang baik untuk generasi penerus bangsa merupakan tanggungjawab bersama terutama untuk anakanak. Hal ini dikarenakan anak-anak masih dalam proses pertumbuhan, baik secara fisik maupun mental. Masih banyak hal yang perlu anak-anak pelajari dan serap di lingkungan rumah, sekolah ataupun di lingkungan sosial.Hal ini menjadi dasar yang kuat bagi seluruh bangsa di dunia untuk sepakat melalui Convention On The Right Of The Child (CRC) bahwa "hak-hak asasi anak harus diberikan dan anak-anak juga memerlukan perlindungan khusus."

Hal ini disambut baik oleh Indonesia dengan menjamin setiap anak memperoleh perlindungan dari kegiatan eksploitasi ekonomi dan setiap pekerjaan yang membahayakan yang dapat mengganggu pendidikan, kesehatan fisik, moral, kehidupan sosial dan mental spiritualnya.(Rumtianing, 2016:8). Dilihat dari kesepakatan tersebut, diperlukan peranan campur tangan dari berbagai pihak untuk menciptakan lingkungan yang pro untuk anak.

Namun kenyataan yang terjadi di kota Semarang sangat memprihatikan. Mengutip data Dinas Pemberdayaan Perempuan Perlindungan Anak Pengendalian Penduduk dan Keluarga Berencana (DP3AKB) Jawa Tengah, kasus kekerasan terhadap anak di Kota Semarang mencapai 195 kasus dimana ini merupakan angka tertinggi di Provinsi Jawa Tengah. Kekerasan yang seringkali terjadi adalah kekerasan seksual, kekerasan fisik, psikis, eksploitasi, trafficking, penelantaran dan lainnya (Gatrra.com, 2019).

Berdasar hal tersebut, kota Semarang memiliki komitmen besar untuk mewujudkan Semarang sebagai Kota Layak Anak (KLA), bahkan menargetkan mendapatkan penghargaan Kota Layak Anak Kategori Utama di tahun 2020. Terdapat beberapa indikator untuk meraih predikat tersebut jika dilihat dari jurnal, yaitu 31 indikator, dimana diklasifikasikan menjadi lima kluster yaitu kluster hak sipil dan kebebasan, kluster lingkungan keluarga dan perawatan alternatif, kluster kesehatan dasar dan kesejahteraan, kluster pendidikan, pemanfaatan waktu luang dan kegiatan budaya dan kluster upaya-upaya perlindungan khusus(Ratri, 2014:3).
Berdasar padalima kluster diatas, dapat dilihat bahwa keluarga memiliki peranyang sangat penting dimana komunikasi yang terjalin antara orang tua dan anak menjadi kunci agar anak memiliki rasa aman.Komunikasi dalam keluarga memiliki banyak peran, selain sebagai proses penyampaian pesan/informasi dalam lingkup keluarga, tetapi juga agar tercipta hubungan yang harmonis antar anggota keluarga yang akhirnya mewujudkan keluarga yang bahagia, sehat jiwa dan raga(Tjitjipo, Senduk, \& Boham, 2018:2) dilihat dari pernyataan tersebut, pendampingan di lingkungan keluarga perlu dilakukan secara berkelanjutan.

Seperti yang dikatakan oleh Arinda Veratamala, bahwa membangun komunikasi dengan anak yang positif sejak anak kecil dapat membantu dalam mengembangkan kepercayaan diri anak, membangun rasa harga diri anak dan merasa lebih berharga, membangun konsep diri anak yang positif dan dapat membantu anak membangun hubungan dengan orang lain (Veratamala, 2019). Pernyataan tersebut, semakin mengkonfirmasi betapa pentingnya menjaga komunikasi di dalam keluarga. Untuk itu, pengabdian masyarakat kali ini memberikan penyuluhan bagaimana berkomunikasi antar anggota keluarga terutama pada anak-anak kepada para kader yang telah terbentuk di Pusat Pelayanan Terpadu Kota Semarang yang ada di setiap tingkat kelurahan, dalam hal ini Kelurahan Sadeng, kecamatan Gunungpati karena JPPA (Jaringan Perlindungan Perempuan dan Anak) yang dibentuk oleh pemerintah yang telah memiliki embrio kader yang cakap adalah JPPAKelurahan Sadeng.

Berdasar hasil wawancara dengan Lurah Kelurahan Sadeng, diperoleh simpulan bahwa persoalan yang dihadapi adalah belum dilakukannya langkah preventif karena selama ini JPPA bergerak hanya saat ada kasus.Selain itu, diperlukan adanya refleksi terkait pemahaman yang selama ini dimiliki oleh para Kader mengenai komunikasi keluarga. Hal ini dikarenakan belum adanya pelatihan khusus tentang komunikasi dan sharing session tentang pengalaman dalam proses pendampingan. Pengabdian dilakukan dengan tujuan mengukur dan meningkatkan pemahaman komunikasi interpersonal dalam keluarga maupun yang dilakukan Kader JPPA Kel. Sadeng dalam proses pendampingan selama ini. 


\section{METODE PELAKSANAAN}

Berikut ini paparan terkait teknis pelaksaaan Kegiatan Pengabdian Masyarakat mengenai komunakasi bagi Kader JPPA Kelurahan Sadeng yang telah dilaksanakan.

\section{Waktu dan Tempat Pelaksanaan}

Kegiatan ini dilaksanakan pada hari Sabtu, 25 Januari 2020 di Balai Kelurahan Sadeng, Gunungpati Semarang.

\section{Alat dan Bahan:}

Alat dan Bahan yang digunakan adalah powerpointsebagai media presentasi, kuesioner sebagai tolok ukur feedback peserta, dan sound system sebagai media saat berdiskusi.

\section{Langkah Pelaksanaan}

Berikut langkah pelaksanaan kegiatan:

1. Melakukan Pre-Test terkait pemahaman para kader JPPA terkait peranan komunikasi keluarga dan Kota Ramah Anak.

2. Memberikan materi tentang Komunikasi Keluarga yang efektif dan perananya dalam langkah preventif kekerasan pada anak(bentuk paparan slide).

3. Mengajak peserta untuk sharing terkait pengalaman mereka mengenai komunikasi keluarga yang selama ini dilakukan.

4. Memberikan materi tentang kekerasan pada anak dan dampaknya baik secara psikologis maupun secara lebih luas disertai beberapa contoh video.

5. Memberikan gambaran mengenai kebutuhan konten pendukung dalam kampanye pencegahan kekerasan pada anak, termasuk di dalamnya komunikasi keluarga.

6. Tanya jawab sebagai feedback tim pengabdian

7. Post-test sebagai feedback yang diperoleh

Pengukuran kemampuan komunikasi interpersonal dilakukan dengan dua tahap yaitu sebelum kegiatan para peserta mengisi pre-test dan setelah kegiatan para peserta mengisi posttest. Pertanyaan yang diberikan untuk pre dan post adalah:

- Pemahaman tentang komunikasi efektif

- Jenis ketrampilan komunikasi yang dilakukan
- Unsur yang mempengaruhi komunikasi

- Gaya komunikasi komunikan dan komunikator

- Bentuk-bentuk Body language yang selama ini dipahami dan dipraktekan

- Membaca tipe kepribadian diri dan orang lain

\section{HASIL DAN PEMBAHASAN}

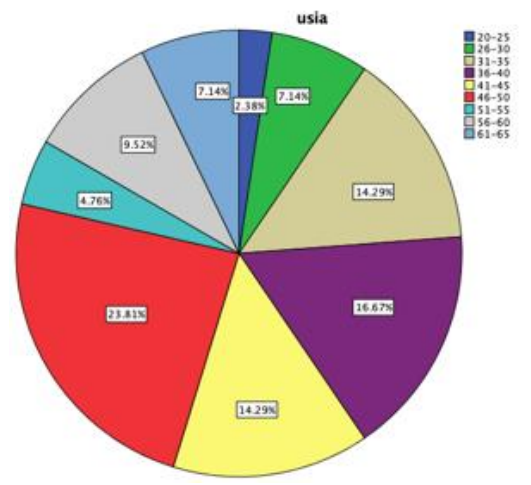

Gambar 1.Usia peserta pelatihan kader JPPA

Usia kader JPPA peserta pelatihan didominasi usia 46-50 tahun sebanyak $23,81 \%$. Dominasi kedua usia 36-40 tahun sebanyak 16,67\%, ketiga usia 31-35 tahun dan usia 41-45 tahun sebanyak $14,29 \%$.

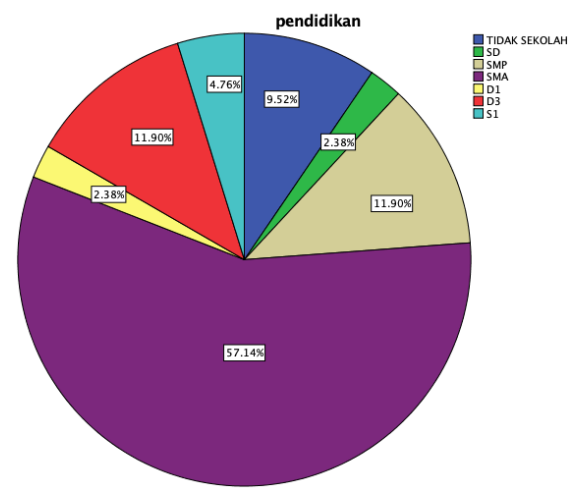

Gambar 2. Pendidikan peserta pelatihan kader JPPA

Pendidikan kader JPPA peserta pelatihan didominasi SMA sebanyak $57,14 \%$. Dominasi kedua SMP dan D3 sebanyak 11,9\%\%. Hal ini menunjukkan bahwa mayoritas kader memiliki tingkat pendidikan menengah dan tinggi, sehingga dianggap mampu menyerap danmengimplementasikan materi pelatihan yangdiberikan 
Tabel 1.Tabel Pre Test

\begin{tabular}{|ll|r|r|r|r|}
\multicolumn{7}{|c|}{$\mathbf{X 1}$} \\
\hline & & Frequency & Percent & Valid Percent & $\begin{array}{c}\text { Cumulative } \\
\text { Percent }\end{array}$ \\
\hline Valid & 2 & 1 & 2.4 & 2.4 & 2.4 \\
& 3 & 10 & 23.8 & 23.8 & 26.2 \\
& 4 & 31 & 73.8 & 73.8 & 100.0 \\
& Total & 42 & 100.0 & 100.0 & \\
\hline
\end{tabular}

\begin{tabular}{|ll|r|r|r|r|}
\multicolumn{7}{|c}{ X2 } \\
\hline & & Frequency & Percent & Valid Percent & $\begin{array}{c}\text { Cumulative } \\
\text { Percent }\end{array}$ \\
\hline Valid & 1 & 1 & 2.4 & 2.4 & 2.4 \\
& 2 & 23 & 54.8 & 54.8 & 57.1 \\
& 18 & 42.9 & 42.9 & 100.0 \\
& Total & 42 & 100.0 & 100.0 & \\
\hline
\end{tabular}

\begin{tabular}{|ll|r|r|r|r|}
\multicolumn{7}{c|}{$\mathbf{X 3}$} \\
\hline & & Frequency & Percent & Valid Percent & $\begin{array}{c}\text { Cumulative } \\
\text { Percent }\end{array}$ \\
\hline Valid & 1 & 1 & 2.4 & 2.4 & 2.4 \\
& 2 & 29 & 69.0 & 69.0 & 71.4 \\
& 12 & 28.6 & 28.6 & 100.0 \\
& Total & 42 & 100.0 & 100.0 & \\
\hline
\end{tabular}

\begin{tabular}{|c|c|c|c|c|c|}
\hline & & Frequency & Percent & Valid Percent & $\begin{array}{c}\text { Cumulative } \\
\text { Percent }\end{array}$ \\
\hline \multirow[t]{4}{*}{$\begin{array}{l}\text { Valid } \\
\end{array}$} & 1 & $\sqrt{2}$ & 4.8 & 4.8 & 4.8 \\
\hline & 2 & 27 & 64.3 & 64.3 & 69.0 \\
\hline & 3 & 13 & 31.0 & 31.0 & 100.0 \\
\hline & Total & 42 & 100.0 & 100.0 & \\
\hline
\end{tabular}

\begin{tabular}{|ll|r|r|r|r|}
\multicolumn{7}{|c|}{ X5 } \\
\hline & & Frequency & Percent & Valid Percent & $\begin{array}{c}\text { Cumulative } \\
\text { Percent }\end{array}$ \\
\hline Valid & 1 & 4 & 9.5 & 9.5 & 9.5 \\
& 2 & 18 & 42.9 & 42.9 & 52.4 \\
& 20 & 47.6 & 47.6 & 100.0 \\
& Total & 42 & 100.0 & 100.0 & \\
\hline
\end{tabular}

\begin{tabular}{|ll|r|r|r|r|}
\multicolumn{7}{c|}{ X6 } \\
\hline & & Frequency & Percent & Valid Percent & $\begin{array}{c}\text { Cumulative } \\
\text { Percent }\end{array}$ \\
\hline Valid & 1 & 3 & 7.1 & 7.1 & 7.1 \\
& 2 & 22 & 52.4 & 52.4 & 59.5 \\
& 17 & 40.5 & 40.5 & 100.0 \\
& Total & 42 & 100.0 & 100.0 & \\
\hline
\end{tabular}

\begin{tabular}{|c|c|c|c|c|c|}
\hline & & Frequency & Percent & Valid Percent & $\begin{array}{l}\text { Cumulative } \\
\text { Percent }\end{array}$ \\
\hline \multirow[t]{4}{*}{$\begin{array}{l}\text { Valid } \\
\end{array}$} & 2 & 11 & 26.2 & 26.2 & 26.2 \\
\hline & 3 & 29 & 69.0 & 69.0 & 95.2 \\
\hline & 4 & 2 & 4.8 & 4.8 & 100.0 \\
\hline & Total & 42 & 100.0 & 100.0 & \\
\hline
\end{tabular}

Tabel 2. Tabel Post Test

\begin{tabular}{|ll|r|r|r|r|}
\multicolumn{7}{|c|}{ X1A } \\
\hline & & Frequency & Percent & Valid Percent & $\begin{array}{c}\text { Cumulative } \\
\text { Percent }\end{array}$ \\
\hline Valid & 3 & 7 & 16.7 & 16.7 & 16.7 \\
& 4 & 35 & 83.3 & 83.3 & 100.0 \\
& Total & 42 & 100.0 & 100.0 & \\
\hline
\end{tabular}

\begin{tabular}{|ll|r|r|r|r|}
\multicolumn{7}{|c|}{ X2A } \\
\hline & & Frequency & Percent & Valid Percent & $\begin{array}{c}\text { Cumulative } \\
\text { Percent }\end{array}$ \\
\hline Valid & 3 & 39 & 92.9 & 92.9 & 92.9 \\
& 4 & 3 & 7.1 & 7.1 & 100.0 \\
& Total & 42 & 100.0 & 100.0 & \\
\hline
\end{tabular}

\begin{tabular}{|ll|r|r|r|r|}
\multicolumn{7}{c|}{ X3A } \\
\hline & & Frequency & Percent & Valid Percent & $\begin{array}{c}\text { Cumulative } \\
\text { Percent }\end{array}$ \\
\hline Valid & 1 & 1 & 2.4 & 2.4 & 2.4 \\
& 2 & 2 & 4.8 & 4.8 & 7.1 \\
& 3 & 38 & 90.5 & 90.5 & 97.6 \\
& 4 & 1 & 2.4 & 2.4 & 100.0 \\
& Total & 42 & 100.0 & 100.0 & \\
\hline
\end{tabular}

\begin{tabular}{|ll|r|r|r|r|}
\multicolumn{7}{|c|}{ X4A } \\
\hline & & Frequency & Percent & Valid Percent & $\begin{array}{c}\text { Cumulative } \\
\text { Percent }\end{array}$ \\
\hline Valid & 2 & 1 & 2.4 & 2.4 & 2.4 \\
& 3 & 39 & 92.9 & 92.9 & 95.2 \\
& 4 & 2 & 4.8 & 4.8 & 100.0 \\
& Total & 42 & 100.0 & 100.0 & \\
\hline
\end{tabular}

\begin{tabular}{|ll|r|r|r|r|}
\multicolumn{7}{|c|}{ X5A } \\
\hline & & Frequency & Percent & Valid Percent & $\begin{array}{c}\text { Cumulative } \\
\text { Percent }\end{array}$ \\
\hline Valid & 1 & 1 & 2.4 & 2.4 & 2.4 \\
& 2 & 2 & 4.8 & 4.8 & 7.1 \\
& 38 & 90.5 & 90.5 & 97.6 \\
& 1 & 2.4 & 2.4 & 100.0 \\
\hline & Total & 42 & 100.0 & 100.0 & \\
\hline
\end{tabular}

\begin{tabular}{|c|c|c|c|c|c|}
\hline \multicolumn{6}{|c|}{$\mathrm{X} 6 \mathrm{~A}$} \\
\hline & & Frequency & Percent & Valid Percent & $\begin{array}{c}\text { Cumulative } \\
\text { Percent }\end{array}$ \\
\hline \multirow{3}{*}{ Valid } & 3 & 41 & 97.6 & 97.6 & 97.6 \\
\hline & 4 & 1 & 2.4 & 2.4 & 100.0 \\
\hline & Total & 42 & 100.0 & 100.0 & \\
\hline
\end{tabular}

\begin{tabular}{|ll|r|r|r|r|}
\multicolumn{7}{|c|}{ X7A } \\
\hline & & Frequency & Percent & Valid Percent & $\begin{array}{c}\text { Cumulative } \\
\text { Percent }\end{array}$ \\
\hline Valid & 3 & 40 & 95.2 & 95.2 & 95.2 \\
& 4 & 2 & 4.8 & 4.8 & 100.0 \\
& Total & 42 & 100.0 & 100.0 & \\
\hline
\end{tabular}

Hasil kuesioner pre dan post-test menunjukkan bahwa pemahaman tentang pentingnya komunikasi efektif meningkat $3,4 \%$ menjadi $100 \%$. Ditunjukkan mayoritas kader menjawab bahwa komunikasi efektif sangat penting karena dapat mewujudkan pemahaman bersama sehingga mampu meminimalisir kesalahpahaman.

Komunikasi efektif dimaknai sebagai munculnya pengertian, mampu menciptakan rasa senang, dapat mempengaruhi sikap, meningkatkan hubungan baik, dan pada tahap terakhir menimbulkan tindakan yang diinginkan (Mulyana, 2008). Berdasar pengertian tersebut, dapat disimpulkan bahwakomunikasi yang efektif menjadi penting untuk bisa secara praktis dilakukan oleh Kader JPPA Kel. Sadeng dalam perannya sebagai pendamping komunikasi keluarga pada lini terendah yang merupakan lini paling dekat dengan masyakarat.

Hasil kuesioner pre dan post-test menunjukkan bahwa pengetahuan tentang jenis-jenis keterampilan komunikasi meningkat $57,1 \%$ menjadi $100 \%$. Mayoritas kader mampu menjawab jenis-jenis keterampilan komunikasi yang menurut mereka paling penting adalah 
keterbukaan, kepercayaan, dan sikap yang ramah. Melalui hal ini, komunikasi dapat berlangsung dengan lebih baik tanpa ada kecurigaan sehingga menjadi efektif.

Changara (2008; Kamaruzzaman, 2016) mengungkapkan keterampilan komunikasi adalah kemampuan yang dimiliki seseorang dalam menyampaikan atau mengirim pesan kepada target khalayaknya. Definisi ini mampu memberikan kejelasan tentang mengapa keterampilan dalam komunikasi antar pribadi adalah kunci untuk para Kader JPPA Kel.Sadeng dapat sukses dalam melakukan pendampingan.

Keterbukaan, kepercayaan dan sikap saling ramah dimaknai sebagai kemampuan dalam komunikasi antar pribadi yang mampu menanggapi dengan senang hati, mampu menerima, dan dapat memunculkan hubungan yang lebih dekat dengan target khalayaknya (Aminudin, 2012). Karakteristik orang yang memiliki sifat terbuka diantaranya, (1) mampu menilai pesan secara objektif, (2) membedakan dengan mudah dalam melihat nuansa dan kondisi, (3) berorientasi pada isi, (4) mencari informasi dari banyak sumber, (5) mampu mendefinisikan pesan yang berbeda dengan system kepercayaan yang telah ada sebelumnya, sehingga tercipta objektivitas (Rahmat, 2007; Aminudin, 2012).

Hasil kuesioner pre dan post-test menunjukkan bahwa pengetahuan tentang unsur-unsur komunikasi meningkat 64,2\% menjadi $92,8 \%$. Mayoritas kader mampu menjawab unsur-unsur komunikasi dan menekankan pada komunikasi empatik, audible, rendah hati, dan efektif.Kader telah memiliki pemahaman, dengan mengaplikasikan unsur-unsur tersebut, komunikasi dapat dilakukan lebih baik bahkan dalam ruang lingkup personal.

Kesadaran tentang pentingnya keberhasilan dalam komunikasi ditunjukkan dengan penekanan unsur-unsur komunikasi itu sendiri. Di mana komunikasi merupakan suatu proses transaksional, semua komponen yang terlibat dalam komunikasi memiliki kebutuhan yang sama dalam hal tanggapan, sehingga komunikasi dapat dikatakan berhasil. Di sisi lain komunikasi juga melibatkan banyak unsur (Liliweri, 2011). Unsur empati dan kerendahan hati dinilai mampu membawa kedekatan hubungan yang lebih pribadi, karena empati adalah kemampuan merasakan apa yang dirasakan oleh orang lain (Aminudin, 2012).
Kader JPPA Kel. Sadeng dinilai memiliki empati yang tinggi untuk mampu masuk dalam ruang pribadi dalam proses pendampingan kepada masyarakat dalam hal perlindungan dari kekerasan baik fisik maupun psikis.

Hasil kuesioner pre dan post-test menunjukkan bahwa pengetahuan tentang gaya-gaya komunikasi meningkat $66,6 \%$ menjadi 97,6\%. Mayoritas kader mampu menjawab beberapa gaya-gaya komunikasi diantaranya kontroling, strukturing, dinamic style, dan komunikasi terbuka.Kader telah memiliki pemahaman, tentang gaya-gaya komunikasi sehingga diharap dapat secara langsung mengimplementasikan dalam kegiatan konseling JPPA.

Gaya komunikasi dimaknai sebagai seperangkat perilaku antar pribadi yang spesial dalam situasi tertentu. Masing-masing gaya komunikasi mengandung perilaku-perilaku komunikasi yang digunakan untuk memperoleh respon dan tanggapan tertentu pula, dalam konteks dan situasi tertentu (Novitasari, 2016). Dapat dikatakan bahwa gaya komunikasi seseorang tidak dapat secara langsungdikategorikan berdasarkan karakteristik pribadi, namun idealnya gaya komunikasi dikategorikan berdasarkan situasi yang dihadapi. Beberapa style yang dipilih oleh mayoritas Kader JPPA Kel. Sadeng tidak dijalankan secara terpisah dalam melakukan pendampingan dan konseling, melainkan beberapa gaya tersebut digabungkan, sehingga mampu menciptakan nuansa komunikasi yang harmonis dan tepat sasaran.

Gaya komunikasi mengontrol merupakan gaya komunikasi yang kental dengan nuansa mengendalikan. Hal ini bertujuan untuk membatasi, memaksa, dan mengatur perilaku orang lain. Sedangkan gaya komunikasi terstruktur digunakan untuk memantapkan perintah atau ajakan. Ditambah gaya komunikasi dinamis yang memiliki kecenderungan agresif agar penerima pesan terangsang untuk melalukan sesuatu dengan lebih baik. Kemudian komunikasi terbuka menjadikan proses komunikasi semakin sempurna, karena penerima pesan diberi ruang untuk menyampaikan cara apa yang paling mereka sukai untuk melakukan perintah atau ajakan yang diinformasikan (Tubbs \& Moss, 2008; Novitasari, 2016).

Hasil kuesioner pre dan post-test menunjukkan bahwa pengetahuan tentang gaya komunikasi yang dimiliki meningkat $45,2 \%$ 
menjadi 92,8\%. Mayoritas kader merasa memiliki gaya komunikasi kontroling dan terbuka. Melihat hal ini kader dianggap telah memiliki bekal untuk menjadi konselor, karena kedua gaya komunikasi ini memiliki sifat dan keluesan tersendiri, dan apabila keduanya digabungkan, akan menjadi gaya komunikasi yang dinilai lebih efektif dalam mempengaruhi orang lain untuk melakukan perintah atau ajakan.

Hasil kuesioner pre dan post-test menunjukkan bahwa pemahaman body language pendukung komunikasi meningkat $59,5 \%$ menjadi $100 \%$. Mayoritas kader telah memiliki pemahaman body language yang paling mendukung dalam berkomunikasi menurut mereka adalah tatap mata dan ekspresi wajah.

Salah satu studi mengungkap bahwa Bahasa tubuh dinyatakan mampu memberikan kesan lebih dalam proses komunikasi, di mana kesan tersebut bergantung pada individu yang menerima pesan atau kode dari Bahasa tubuh yang digunakan (Hidayat, 1970). Bahasa tubuh merupakan elemen komunikasi non verbal yang sangat penting untuk mendukung pengungkapan dan penyampaian sebuah pesan.Paul Ekman mengungkap beberapa pesan nonverbal dari pandangan mata, diantaranya, (1) emblem, gerakan mata tertentu yang dipahami sebagai sebuah tanda.Seperti mengedipkan mata lebih cepat dapat diisyaratkan sebagai, "saya tidak bersunggungsungguh". (2) Ilustrator, pandangan ke bawah yang berarti depresi atau kesedihan. (3) Regulator, ada atau tidak adanya kontak mata yang dapat diartikan sebagai penerimaan dan penolakan. (4) Penyesuai, orang-orang yang berada dalam tekanan dipercaya akan lebih cepat mengedipkan mata ketika dijak berkomunikasi. (5) Affect display, pembesaran pupil yang diartikan sebagai peningkatan emosi, seperti marah, senang, dan terkejut (Griffin, 1991; Hasanah, 2014)

Hasil kuesioner pre dan post-test menunjukkan bahwa pengetahuan tentang tipe kepribadian yang dimiliki meningkat 26,2\% menjadi $100 \%$. Berdasar hasil jawaban yang mereka berikan mayoritas merasa memiliki tipe kepribadian plegmatis sebanyak 18 orang, melankolis 8 orang, sanguine 6 orang, dan korelis 4 orang.

Setiap orang memiliki karakter dasar masing-masing.Hal ini melandasi perilaku yang dimunculkan dalam interaksi pribadi maupun
sosialnya.Empat karakter yang sudah sangat massif dikenal adalah sanguine, plegmatis, melankolis, dan corelis. Keempat karakter ini mampu memberikan nuansa yang berbeda pada setiap proses komunikasi yang dilakukan. Sanguin dikenal memiliki kecenderungan selalu ceria dan bersemangat.Melankolis biasanya disematkan pada orang-orang yang lebih mudah menangis, hatinya lembut dan sangat sensitif. Corelis adalah karakter untuk orang-orang yang kuat dan biasanya cenderung mengontrol orang lain. Terakhir, plegmatis adalah orang-orang yang lebih suka kedamaian, menghindari konflik dan menyukai ketenangan (Hidayati, 2018). Berdasar hasil tes pada Kader JPPA Kel.Sadeng, diketahui mayoritas memiliki karakter plegmatis, orang-orang yang lebih suka kedamaian dan selalu berusaha menghindari konflik, di mana hal ini dinilai sangat baik untuk karakter seorang konselor.

Luaran dari pengabdian yang telah dilaksanakan adalah unggahan di media sosial (youtube dan instagram) dan portal online.Hakikatnya pengabdian masyarakat adalah untuk memenuhi persepsi masyarakat terkait beberapa hal diantaranya (a) pusat pengkajian dan pengembangan IPTEKS, (b) pusat pembaharuan dan modernisasi, (c) pusat kebudayaan masyarakat yang memiliki perguruan tinggi, (d) sumber pakar status sosial, serta (e) sumber belajar mahasiswa (Riduwan, 2016). Demi memenuhi persepsi tersebut, menjadi penting sebuah pengabdian masyarakat dipublikasikan.Berikut hasil publikasi pengabdian masyarakat yang telah dilakukan:

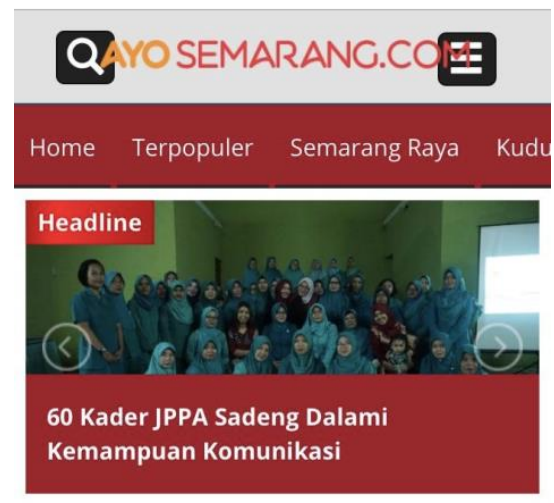

Sumber:

https://m.ayosemarang.com/read/2020/01/26/51233/ 60-kader-jppa-sadeng-dalami-kemampuankomunikasi Gambar 3. Publikasi pengabdian masyarakat di media massa 
Berikut ini publikasi video kegiatan di media sosial youtube ilkom mengabdi dan publikasi foto kegiatan di media instagram ilkom mengabdi:

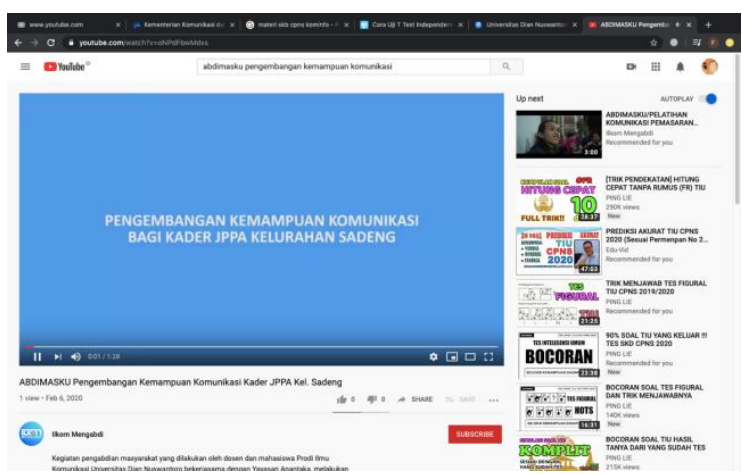

Gambar 4. Publikasi kegiatan melalui Youtube

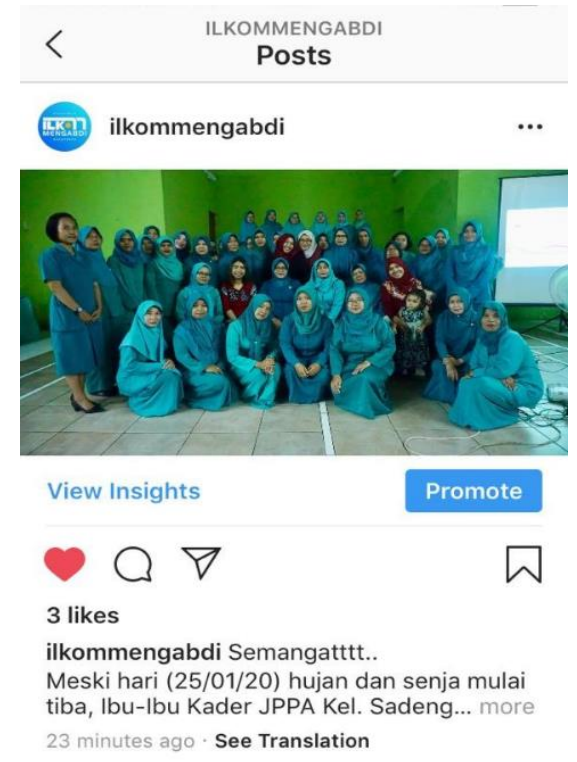

Gambar 5.Publikasi kegiatan melalui Instagram.

\section{SIMPULAN DAN SARAN}

Berdasar hasil kuesioner pre-test dan posttest, pelatihan yang dilakukan dalam upaya peningkatan kemampuan komunikasi Kader JPPA Kelurahan Sadeng dinilai memiliki efisiensi dan tepat guna. Pemahamanpemahaman yang kini telah dimiliki Kader JPPA Kelurahan Sadeng setelah mendapat pelatihan adalah pentingnya komunikasi efektif, jenis-jenis keterampilan komunikasi, unsur-unsur komunikasi, gaya-gaya komunikasi, mengenali gaya komunikasi yang dimiliki, pentingnya body language dalam mendukung komunikasi efektif, dan mengenali tipe-tipe kepribadian.
Peningkatan kemampuan pada setiap unsurnya berbeda, namun secara dominan peningkatan terjadi pada pengetahuan tentang pentingnya komunikasi efektif, unsur komunikasi, dan pentingnya body language dalam melakukan proses komunikasi, baik dalam pendampingan maupun konsultasi. Berdasar hal ini dapat disimpulkan bahwa pelatihan peningkatan kemampuan komunikasi untuk Kader JPPA Kel.Sadeng memiliki kebermanfaatan, tepat guna, dan tepat sasaran.

Pelatihan ini diharapkan mampu menjadi projek perdana yang berkelanjutan.Pelatihan juga diharapkan dapat dilakukan secara merata pada setiap kelurahan yang memiliki bentukan Kader JPPA.Diperlukan peran serta para pemangku kepentingan untuk berkolaborasi dan bekerjasama, di mana hal ini ideal untuk dilakukan dalam mewujudkan Kota Semarang Ramah Anak.

\section{UCAPAN TERIMA KASIH}

Ucapan terima kasih kami sampaikan kepada LPPM Universitas Dian Nuswantoro dan Kelurahan Sadeng sebagai mitra kegiatan pengabdian masyarakat. Terimakasih atas kolaborasi awal yang terjalin antara ilmu komunikasi Udinus dengan Anantaka cultural trust.

\section{DAFTAR PUSTAKA}

Aminudin, D. (2012). Efektivitas Bimbingan Teman Sebaya Dalam Meningkatkan Kemampuan Komunikasi Interpersonal Siswa, 15-63.

Gatrra.com. (2019). Angka Kasus Kekerasan terhadap Anak di Jateng Masih Tinggi. Retrieved from https://www.gatra.com/

detail/news/409870-Angka-Kasus-Kekerasanterhadap-Anak-di-Jateng-Masih-Tinggi

Hasanah, F. (2014). Fungsi Bahasa Tubuh Dan Komunikasi Nonverbal Dalam Komunikasi Antar Pribadi, 1-9.

Hidayat, A. (1970). Bahasa Tubuh: Tanda Dalam Sistem Komunikasi. KOMUNIKA: Jurnal Dakwah Dan Komunikasi, 4(2), 224-234. https://doi.org/10.24090/ komunika.v4i2.151

Hidayati, R. (2018). DIMENSI PSIKOLOGIS MANUSIA. Kudus: Universitas Muhammadyah Kudus. Retrieved from https://eprints.umk.ac.id/11736/2/DIMENS I BOOK.pdf 
Kamaruzzaman, K. (2016). Analisis Keterampilan Komunikasi Interpersonal Siswa. Jurnal Konseling Gusjigang, 2(2), 202-210. https://doi.org/10.24176/

jkg.v2i2.744

Liliweri, A. (2011). Komunikasi Serba Ada Serba Makna. Jakarta: Kencana Prenada Media Group.

Mulyana, D. (2008). Komunikasi Efektif. Bandung: PT. Remaja Rosda Karya.

Novitasari, I. (2016). Studi Deskriptif Gaya Komunikasi, (2000), 22-25.

Ratri, D. K. (2014). Implementasi Peraturan Walikota Nomor 36 Tahun 2013 Tentang Kebijakan Kota Layak Anak. Jurnal Ilmu Pemerintah UB, 1(2), 12.

Riduwan, A. (2016). Pelaksanaan Kegiatan Pengabdian. EKUITAS (Jurnal Ekonomi Dan Keuangan), 3. https://doi.org/DOI: 10.24034/j25485024.y1999.v3.i2.1886

Rumtianing, I. (2016). Kota layak anak dalam perspektif perlindungan anak. Jurnal Ilmiah Pendidikan Pancasila Dan Kewarganegaraan, 27(1), 7-23. https://doi.org/10.17977/JPPKN.V27I1.552 4

Tjitjipo, K., Senduk, J. J., \& Boham, A. (2018). Peran Kepemimpinan Dalam Meningkatkan Kenerja Staf Di Dinas Kearsipan Dan Perpustakaan Kabupaten Halmahera Utara. ACTA DIURNA KOMUNIKASI, 7(4).

Veratamala, A. (2019). Kenapa Orangtua Wajib Rutin Berkomunikasi Dengan Anak. Retrieved from https://hellosehat.com/ parenting/tips-parenting/pentingnyakomunikasi-dengan-anak/ 